02

\title{
Спектральные проявления взаимодействия наночастиц диоксида кремния с молекулами фотохромных соединений
}

\author{
() В.А. Барачевский ${ }^{1,3}$, О.И. Кобелева ${ }^{1}$, А.М. Горелик ${ }^{1}$, М.М. Краюшкин ${ }^{2}$ \\ ${ }^{1}$ Центр фотохимии ФНИЦ „Кристаллография и фотоника“ РАН, \\ 119333 Москва, Россия \\ ${ }^{2}$ Институт органической химии им. Н.Д. Зелинского РАН, \\ 119991 Москва, Россия \\ ${ }^{3}$ Межведомственный центр аналитических исследований РАН, \\ 117997 Москва, Россия \\ e-mail: barva@photonics.ru
}

Поступила в редакцию 27.04.2018 г.

\begin{abstract}
Проведено сравнительное спектрально-кинетическое исследование водно-этанольных фотохромных систем, содержащих фотохромные соединения из класса спиропиранов, спирооксазинов, хроменов и диарилэтенов без и в присутствии наночастиц диоксида кремния. Установлено, что в завимости от структуры соединения молекулы могут вступать в химическое или физическое взаимодействие с поверхностью наночастиц.
\end{abstract}

DOI: $10.21883 /$ OS.2018.09.46549.116-18

\section{Введение}

Развитие и расширение областей применения нанотехнологий требует создания наночастиц и на их основе материалов с новыми функциональными свойствами. К числу таких инновационных наноматериалов относятся фотохромные наноструктурированные системы, обратимо изменяющие абсорбционные, флуоресцентные, рефрактивные, электрические, механические и другие свойства под действием света [1].

Особый интерес вызывает разработка фотохромных наноструктурированных систем типа ядро-оболочка на основе наночастиц диоксида кремния $\left(\mathrm{SiO}_{2}\right)$ в связи с широкими возможностями их применения в биологической и медицинской диагностике в качестве флуоресцентных меток, в текстильной промышленности для создания фотохромной одежды и камуфляжных покрытий и др. Такие фотохромные наночастицы могут обладать более приемлемыми спектрально-кинетическими свойствами по сравнению с фотохромными соединениями в полимерных слоях вследствие большего свободного молекулярного объема, необходимого для осуществления фотохромных превращений.

В результате ранее выполненных исследований показана возможность получения фотохромных систем с обратным фотохромизмом на основе дендримерных наночастиц диоксида кремния и нитро- $[2,3]$, а также гидроксизамещенных индолиновых спиропиранов $[4,5]$. Обратный фотохромизм наночастиц диоксида кремния обнаружен и при использовании катионных спиропиранов [6]. Положительный фотохромизм на поверхности этих наночастиц проявляют нитрозамещенные спиропираны с длинным метиленовым заместителем при атоме азота индолинового фрагмента [7]. При этом оказалось, что увеличение длины цепоч- ки приводит к возрастанию скорости темновой релаксации фотоиндуцированной мероцианиновой формы. С использованием нитрозамещенного спиропирана и флуорофора Родамина В, молекулы которых были хемосорбированы на поверхности наночастиц диоксида кремния, реализована фотоиндуцированная модуляция флуоресценции флуорофора [8]. Для придания фотохромных свойств коллоидным частицам диоксида кремния использовался сополимер метилметакрилата, содержащий фрагменты нитрозамещенного спиропирана [9-11].

Наночастицы диоксида кремния с адсорбированными молекулами спирооксазина проявляли положительный фотохромизм и использовались для получения фотохромных тканей [12-16]. С той же целью разрабатывались фотохромные наночастицы диоксида кремния, полученные путем ковалентной иммобилизации фотохромных силилированных нафтопиранов (хроменов) [17-19].

Фотохромные монослои на кварцевой подложке были получены в результате взаимодействия молекул диарилэтенов, содержащих силоксановые группы, с поверхностью кварцевого стекла [20]. Показано, что на эффективность фотохромных превращений влияет размер пор в мезаморфном диоксиде кремния [21]. Фотохромные наночастицы диоксида кремния были получены также с использованием полистирола, модифицированного молекулами диарилэтена [22].

В настоящей работе представлены результаты сравнительного спектрального исследования фотохромизма ряда соединений из классов терморелаксирующих спиропиранов, спирооксазинов и хроменов, а также термически необратимых диарилэтенов при взаимодействии с наночастицами диоксида кремния с целью выявления особенностей взаимодействия молекул этих фотохромных соединений с поверхностью наночастиц. 


\section{Экспериментальная часть}

В качестве объектов исследования были выбраны спиропиран 1, спирооксазин 2, хромен 3 и диарилэтены 4-6. Соединения $\quad 1^{\prime}, 3^{\prime}$-дигидро-8-метокси-1', $3^{\prime}, 3^{\prime}$-нитроспиро[2Н-1-бензопиран-2,2'-(2Н)-индол] (1) и 1,3-дигидро1,3,3-триметилспиро[2Н-индол-2,3'-[3Н]нафто[2, 1-b][1,4] оксазин (2) являются коммерческими продуктами (Aldrich). По ранее описанным методикам синтезированы 3-(4-Метоксифенил)-3-(2-тиенил)-5-морфолинокарбонил-3Н-нафто[2,1-b] пиран (3) [23], 2,2'-(перфторциклопент-1- ен - 1, 2-диил )- бис -( $5^{\prime}$-метилтиофенил - $\left.4^{\prime}\right)$ - оксиметил (4) [24], 3-(2,5-Диметилтиофен-3-ил)-4-(2гептил -1-бензотиофен -3-ил)циклопент -3- ен-1, 2-дион -1оксим (5) [25] и 2,2'-(перфторциклопент-1-ен-1,2-диил)бис-(5-метилтиофен-4,2-диил)-бис-(метан-1-ил-иллиден)бис-(N-о-толилфенилгидразинкарботиоамид) (6) [26].<smiles>CCCCCN(C)C(=O)c1cc2ccccc2c2c1OC(c1ccc(OC)cc1)(c1cccs1)C=C2</smiles><smiles>Cc1ccc(NC(=S)N/N=C/c2cc(C3=C(c4cc(/C=N/NC(=S)Nc5ccc(C)cc5)sc4C)CCC3)c(C)s2)cc1</smiles>

Фотохромные соединения растворялись в этаноле и водно-этанольных смесях (1:1 по объему), в которых содержались наночастицы диоксида кремния Левасил 200 („Bayer“, Германия). Растворы соединений в этаноле смешивались с водным раствором наночастиц $\mathrm{SiO}_{2}$, разбавленном в 10 раз, в объемном отношении $1: 1$. Концентрация фотохромных соединений в растворах составляла $C=2 \cdot 10^{-4} \mathrm{M}$.

Спектрофотометрические измерения (фотостационарные спектры и спектры термического обесцвечивания фотоиндуцированной формы) исследуемых соединений в растворах проводили с использованием спектрометра „Cary 50 bio“. Для измерения применяли кварцевые кюветы толщиной $02 \mathrm{~cm}$.

Облучение осуществляли фильтрованным светом осветителя LC-4 („Hamamatsu“, Япония).

\section{Результаты и их обсуждение}

Спектры поглощения наночастиц диоксида кремния в водном и водно-спиртовом растворах не имеют полос поглощения в спектральной области более $300 \mathrm{~nm}$.

Результаты спектрального исследования фотохромных систем без и в присутствии наночастиц $\mathrm{SiO}_{2}$, а также эффективности их фотохромных превращений, оцениваемой по величине фотоиндуцированного изменения оптической плотности в максимуме полосы поглощения фотоиндуцированной формы, представлены на рис. 1-4 и в таблице.

Раствор спиропирана 1 в этаноле в исходном состоянии А имеет слабую окраску, о чем свидетельствует наличие полосы поглощения в видимой области спектра с максимумом при $560 \mathrm{~nm}$ (рис. 1, кривая 1). Это обусловлено тем, что часть молекул спиропирана в этом полярном растворителе присутствует в мероцианиновой

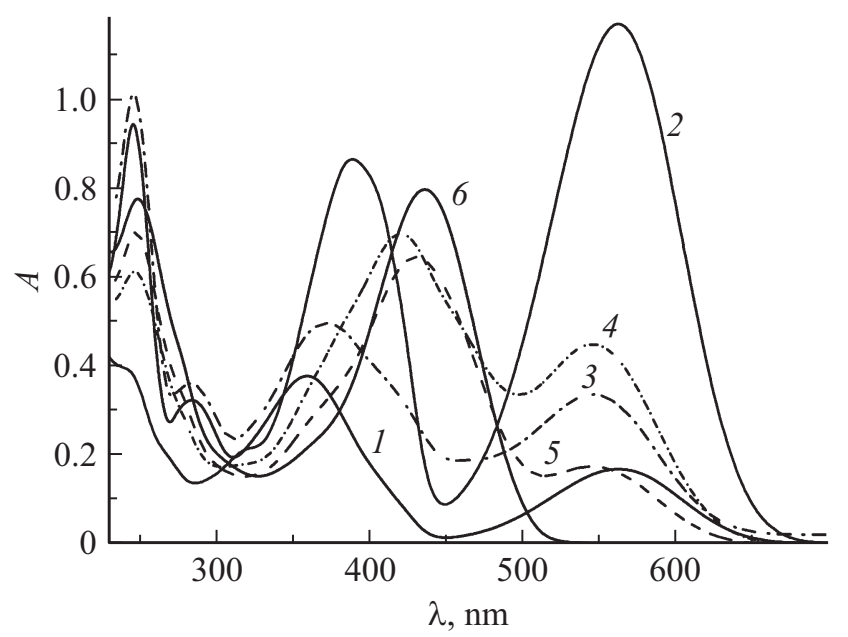

Рис. 1. Спектры поглощения водно-спиртового раствора соединения 1 без $(1,2)$ и в присутствии наночастиц $\mathrm{SiO}_{2}(3-6)$ до $(1,3)$ и после УФ облучения через светофильтр УФС-1 $(2,4)$, воздействия видимым светом через светофильтр ЖС-16 (5) и длительной термической релаксации (6). 
Спектральные характеристики исходной и фотоиндуцированной форм фотохромных соединений без и в присутствии наночастиц диоксида кремния

\begin{tabular}{|c|c|c|c|c|}
\hline Фотохромная система & Агрегатное состояние & $\lambda_{\mathrm{A}}, \mathrm{nm}$ & $\lambda_{\mathrm{B}}, \mathrm{nm}$ & $\Delta D_{\mathrm{B}}^{\text {фот }}$ \\
\hline 1 & Раствор вода/спирт & 354 & 560 & 1.17 \\
\hline $\mathbf{1}+$ Левасил 200 & & 370 & 546 & 0.45 \\
\hline 2 & & 315 & 610 & 1.37 \\
\hline $2+$ Левасил 200 & & 315 & 610 & 1.30 \\
\hline 3 & & 358 & 510 & 0.41 \\
\hline $3+$ Левасил 200 & & 346 & 510 & 0.41 \\
\hline 4 & & 237 & 516 & 0.11 \\
\hline 4 + Левасил 200 & & 237 & 513 & 0.11 \\
\hline 5 & & 353 & 590 & 0.16 \\
\hline 5 + Левасил 200 & & 320 & 570 & 0.15 \\
\hline 6 & & 342 & 635 & 0.60 \\
\hline $6+$ Левасил 200 & & 342 & 660 & 0.67 \\
\hline 6 & Аморфная пленка & 373 & 665 & 0.05 \\
\hline $6+$ Левасил 200 & Поликристаллическая пленка & 335 & 635 & 0.02 \\
\hline
\end{tabular}

Примечание. $\lambda_{\mathrm{A}}$ и $\lambda_{\mathrm{B}}$ - длины волн максимумов полос поглощения исходной и фотоиндуцированной форм фотохромных соединений соответственно; $\Delta D_{\mathrm{B}}^{\text {фот }}$ - величина изменения фотоиндуцированной оптической плотности в максимуме полосы фотоиндуцированной формы в состоянии фоторавновесия.

форме В. При УФ облучении интенсивность этой полосы поглощения возрастает (рис. 1, кривая 2), а облучение раствора видимым светом приводит практически к полному обесцвечиванию раствора. Эти результаты свидетельствуют о положительном фотохромизме этих соединений согласно схеме 1 [27].

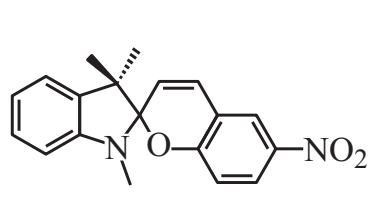

A

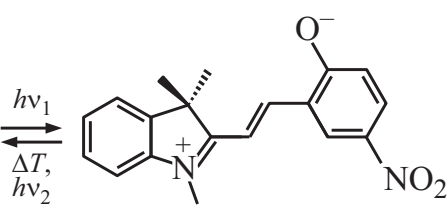

B

\section{Схема 1}

При добавлении в раствор наночастиц диоксида кремния интенсивность длинноволновой полосы поглощения возрастает, а также появляется плечо полосы поглощения при $420 \mathrm{~nm}$ (рис. 1, кривая 3). УФ облучение приводит к дальнейшему повышению интенсивности полос при 560 и $420 \mathrm{~nm}$ (рис. 1, кривая 4). Под действием видимого света интенсивность полосы поглощения при $560 \mathrm{~nm}$ падает, а поглощение с максимумом при $420 \mathrm{~nm}$ возрастает (рис. 1, кривая 5). Полоса, возникающая после длительной темновой релаксации (рис. 1, кривая 6), стабильна и не изменяется при воздействии УФ и видимого света. Эту полосу поглощения следует отнести к образованию протонированной мероцианиновой формы $[4,5]$. Отсутствие отрицательного фотохромизма, возможно, обусловлено агрегацией и кристаллизацией этой формы на поверхности наночастиц $\mathrm{SiO}_{2}$.

В отличие от спиропирана $\mathbf{1}$, спирооксазин 2 , испытывающий подобные фотохромные превращения (схема 2) [27], не проявляет спектральных различий ни в исходном, ни в фотоиндуцированном состоянии в присутствии наночастиц диоксида кремния (таблица).

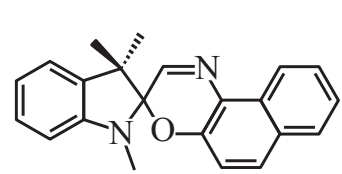

A

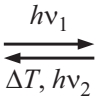

Схема 2
Эффективность фотохромных превращений также оказалась сравнимой (таблица). Следовательно, в отличие от спиропирана 1 химическое взаимодействие между

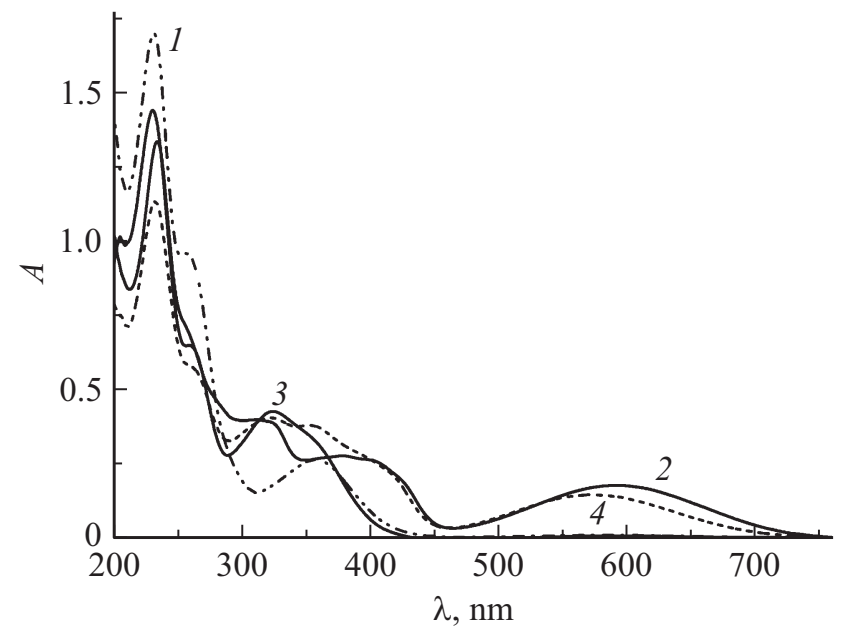

Рис. 2. Спектры поглощения водно-спиртового раствоpa соединения 5 без $(1,2)$ и в присутствии наночастиц $\mathrm{SiO}_{2}(3,4)$ до $(1,3)$ и после УФ облучения через светофильтр УФС-1 $(2,4)$. 


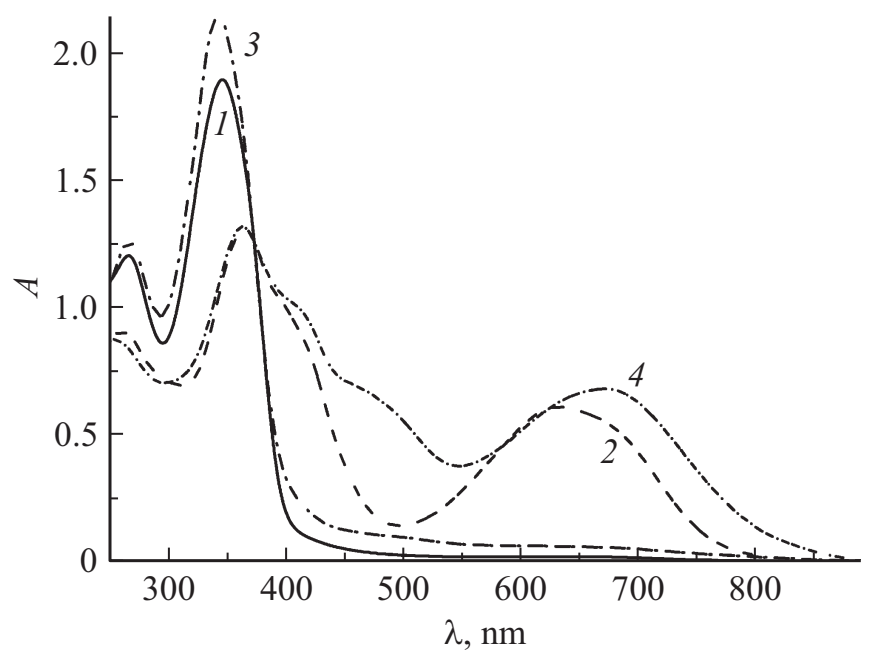

Рис. 3. Спектры поглощения водно-спиртового раствора соединения 6 без $(1,2)$ и в присутствии наночастиц $\mathrm{SiO}_{2}(3,4)$ до $(1,3)$ и после УФ облучения $(3,4)$ через светофильтр УФС1.

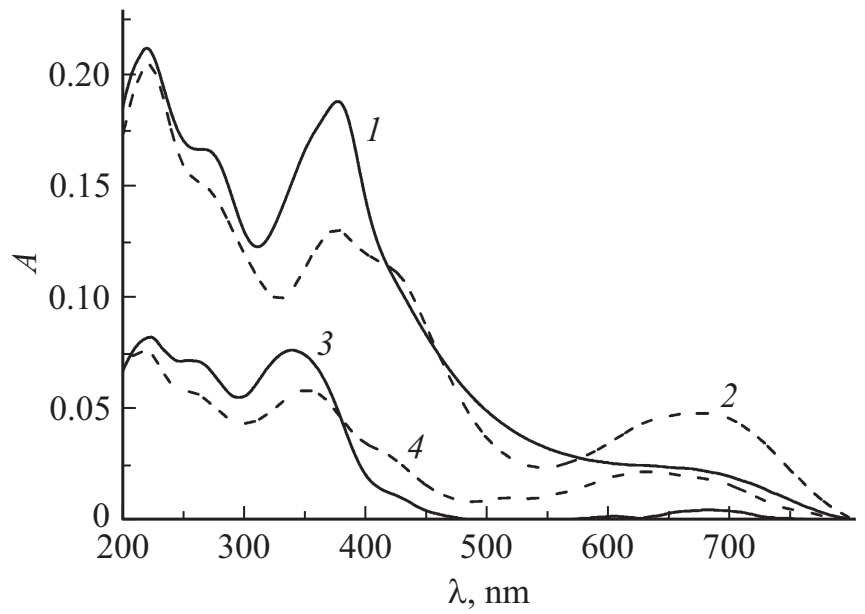

Рис. 4. Спектры поглощения аморфной $(1,2)$ и поликристаллической $(3,4)$ пленок диарилэтена 6 на кварцевом стекле, полученных из водно-этанольного раствора без $(1,2)$ и в присутствии наночастиц $\mathrm{SiO}_{2}(3,4)$ до $(1,3)$ и после УФ облучения $(2,4)$ через светофильтр УФС-1.

молекулами спирооксазина 2 и поверхностью наночастиц $\mathrm{SiO}_{2}$ отсутствует. Наблюдаемое снижение скорости темновой релаксации фотоиндуцированной мероцианиновой формы может свидетельствовать о физической адсорбции молекул на поверхности наночастиц диоксида кремния. Обнаруженное в ходе исследования повышение устойчивости к необратимому фотопревращению молекул спирооксазина 2 в присутствии наночастиц диоксида кремния, по-видимому, обусловлено частичным поглощением активирующего УФ излучения наночастицами.

Аналогичные данные получены для хромена 3 (таблица), проявляющего фотохромные превращения по аналогичной схеме (схема 3) [27]. В отличие от иссле- дованных спиропирана 1 и спирооксазина 2 хромен 3 характеризуется наиболее коротковолновой полосой поглощения фотоиндуцированной мероцианиновой формы (таблица).<smiles>C1=CC(c2ccccc2)(c2ccccc2)Oc2ccc3ccccc3c21</smiles>

A

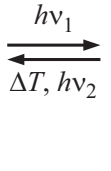

Схема 3
По сравнению с рассмотренными выше спиросоединениями и хроменом фотохромные диарилэтены, как правило, не проявляют термическую релаксацию (схема 4) [27]. Фотохромные превращения открытой формы А в циклическую форму В осуществляются только под действием света, поглощаемого соответствующими формами.

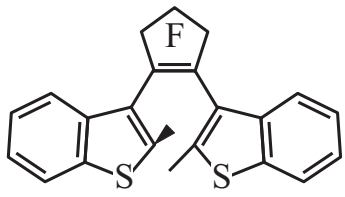

A

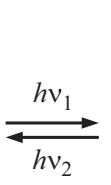

Схема 4

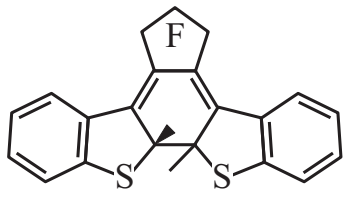

B
Диарилэтен 4, судя по спектрам поглощения открытой и циклической форм (таблица), не испытывает ковалентного взаимодействия с поверхностью наночастиц диоксида кремния. Однако для него обнаружена темновая релаксация фотоиндуцированного циклического изомера В в исходную открытую форму в присутствии наночастиц диоксида кремния. Такое явление превращения термически необратимых диарилэтенов в термически релаксирующие наблюдалось в ацетонитрильных растворах диэтиламинопроизводных диарилэтена при добавлении трифторметансульфоновой кислоты [28].

В отличие от диарилэтена 4 полоса поглощения фотоиндуцированной циклической формы соединения $\mathbf{5}$ испытывает гипсохромное смещение на $20 \mathrm{~nm}$ (рис. 2, таблица).

Подобные спектральные изменения, но более ярко выраженные, наблюдались в спектрах поглощения диарилэтена 6 (рис. 3, таблица).

Как видно из рис. 3, спектр циклической формы соединения в присутствии наночастиц диоксида кремния изменился. В отличие от соединения 5 максимум полосы окрашенной формы сдвинулся не в коротковолновую, а в длинноволновую спектральную область на $30 \mathrm{~nm}$ (рис. 3, кривая 4). При этом в присутствии наночастиц диоксида кремния появляется новая полоса поглощения 
с максимумом при $500 \mathrm{~nm}$. Как и в случае соединения 5, окрашенная циклическая форма релаксирует в темноте в открытую форму. При этом интенсивность полосы поглощения при $500 \mathrm{~nm}$ возрастает. Видимый свет и повторное УФ облучение не оказывают влияния на процессы обесцвечивания и окрашивания растворов. Фотохромизм исчезает подобно нитрозамещенным спиропиранам, адсорбированным на поверхности наночастиц $\mathrm{SiO}_{2}$.

Для исследования влияния наночастиц диоксида кремния в твердофазных пленках были приготовлены водноспиртовые растворы диарилэтена 6 с концентрацией соединения $C=1 \cdot 10^{-2} \mathrm{M}$ без и в присутствии наночастиц диоксида кремния. Обнаружено, что пленка с чистым соединением имела аморфную структуру, а пленка с наночастицами $\mathrm{SiO}_{2}$ была кристаллической. При этом кристаллы плохо удерживались на поверхности кварцевого стекла.

Как следует из анализа спектральных данных (рис. 4, таблица), максимум полосы поглощения фотоиндуцированной циклической формы в твердофазной пленке, содержащей наночастицы $\mathrm{SiO}_{2}$, сдвинут в коротковолновую спектральную область на $30 \mathrm{~nm}$ относительно максимума полосы поглощения этой формы в отсутствие наночастиц диоксида кремния. Возможно, это обусловлено различием в упаковке молекул циклической формы В в аморфной и поликристаллической пленках.

\section{Заключение}

В результате сравнительного спектрально-кинетического исследования фотохромизма фотохромных систем на основе водно-этанольных растворов фотохромных соединений из классов спиросоединений (спиропиранов и спирооксазинов), хроменов и диарилэтенов без и в присутствии наночастиц диоксида кремния установлено, что в зависимости от структуры фотохромных соединений взаимодействие молекул фотохромных соединений с поверхностью наночастиц носит характер химической или физической адсорбции. Химическое взаимодействие проявляется в спектральных сдвигах полос поглощения фотоиндуцированной формы для соединений 1, 5, 6. При этом возможна потеря фотохромных свойств адсорбированных молекул вследствие протонирования молекул на поверхности наночастиц. Для соединений 2 и 3 наблюдается физическое взаимодействие без изменения спектральных характеристик, проявляющееся в замедлении кинетики релаксации мероцианиновой формы этих соединений в исходное циклическое состояние в темноте в присутствии наночастиц диоксида кремния.

Работа выполнена частично при поддержке РФФИ (проект № 18-03-00650) в части спектрально-кинетических и фотохимических исследований, а также РНФ (грант № 14-50-00126) в части синтеза диарилэтенов.

\section{Список литературы}

[1] Barachevsky V.A. // Org. Photonics. Photovolt. 2015. V. 3. P. 8.

[2] Yamaguchi T., Maity A., Polshettiwar V., Ogawa M. // J. Phys. Chem. A. 2017. V. 121. N 42. P. 8080.

[3] Yamaguchi T., Maity A., Polshettiwar V., Ogawa M. // Inorg. Chem. 2018. V. 57. N 7. P. 3671.

[4] Kinashi K., Nakamura S., Imamura M., Ishida K., Ueda Y. // J. Phys. Org. Chem. 2012. V. 25. P. 462.

[5] Kinashi K., Nakamura S., Ono Y., Ishida K., Ueda Y. // J. Photochem. Photobiol. A. 2010. V. 213. P. 136.

[6] Leaustic A., Dupont A., Yu P., Clement R. // New J. Chem. 2001. V. 25. P. 1297.

[7] Ueda M., Kudob K., Ichimura K. // J. Mater. Chem. 1995. V. 5. N 7. P. 1007.

[8] May F., Peter M., Hutten A., Prodi L., Mattay J. // Chem. Eur. J. 2012. V. 18. P. 814.

[9] Piech M., George M.C., Bell N.S., Braun P.V. // Langmuir. 2006. V. 22. P. 1379.

[10] Piech M., Bell N.S. // Macromolecules. 2006. V. 39. N 3. P. 915.

[11] Samanta S., Locklin J. // Langmuir. 2008. V. 24. P. 9558.

[12] Ayazi-Yazdi S., Karimi L., Mirjalili M., Karimnejad M. // J. Text. Institute. 2016. P. 1.

[13] Cheng T., Lin T., Brady R., Wang X. // Fibers and Polymers. 2008. V. 9. N 3. P. 301.

[14] Cheng X., Lin T., Fang J., Brady R. // Text. Res. J. 2007. V. 77. N 12. P. 923.

[15] Lin T., Cheng T., Brady R., Wang X. // Adv. Sci. Technol. 2008. V. 60. P. 21.

[16] Parhizkar M., Zhao Y., Wang X., Lin T. // J. Engin. Fiber. Fabrics. 2014. V. 9. N 3. P. 65.

[17] Pinto T.V., Costa P., Sousa C.M., Sousa C.A.D., Pereira C., Silva C.J.S.M., Pereira M.F.R., Coelho P.J., Freire C. // ACS Appl. Mater. Interfaces. 2016. V. 8. P. 28935.

[18] Pinto T.V., Costa P., Sousa C.M., Sousa C.A.D., Pereira C., Silva C.J.S.M., Pereira M.F.R., Coelho P.J., Freire C. // ACS Appl. Mater. Interfaces. 2016. V. 8. P. 7221.

[19] Pinto T.V., Costa P., Sousa C.M., Sousa C.A.D., Pereira C., Silva C.J.S.M., Pereira M.F.R., Coelho P.J., Freire C. // Dalton Trans. 2017. V. 46. P. 9076.

[20] Nishi H., Kobatake S. // Chem. Lett. 2010. V. 39. P. 638.

[21] Okada H., Nakajima N., Tanaka T., Iwamoto M. // Angew. Chem. Int. Ed. 2005. V. 44. P. 7233.

[22] Seno R., Kobatake S. // Dyes and Pigments. 2015. V. 114. P. 166.

[23] Arsenov V.D., Gorelik A.M., Strokach Yu.P., Barachevsky V.A., Alfimov M.V. // European Patent EP 1038870 A1. 09.27.2000.

[24] Krayushkin M.M., Uzhinov B.M., Martynkin A.Yu., Dzhavadov D.L., Kalik M.A., Ivanov V.L., Stoyanovich F.M., Uzhinova L D., Zolotarskaya O.Yu. // J. Photoenergy. 1999. V. 1 P. 183.

[25] Лоншаков Д.В., Ширинян В.З., Львов А.Г., Краюшкин М.М. // Изв. АН, сер. хим. 2012. № 9. С. 1753.

[26] Краюткин М.М., Личицкий Б.В., Дудинов А.А., Кузнецова О.Ю., Кобелева О.И., Валова Т.М., Барачевский В.А. // Изв. АН, сер. хим. 2010. № 5. С. 1023.

[27] Photochromic Materials. Preparation, Properties and Applications. Eds. H. Tian, J. Zhang. Wiley-VCH Verlag $\mathrm{GmbH} \&$ Co. KGaA, Boschstr. 12, 69469 Weinheim, Germany, 2016. 420 p.

[28] Kobatake S., Terakawa Y. // Chem. Commun. 2007. P. 1698. 